\title{
Vasikoiden melualtistus pihattonavetoissa
}

Sirpa Jokinen ${ }^{1)}$, Suvi Pekkanen ${ }^{2)}$, Risto Kauppinen ${ }^{2)}$, Erkki Björk ${ }^{1)}$, Jaakko Mononen ${ }^{3)}$, Kristiina Dredge ${ }^{4)}$, Veikko Tuovinen $^{2)}$, Kyösti Louhelainen ${ }^{5)}$, Esko Rytkönen ${ }^{5)}$, Jukka Mäittälä ${ }^{5)}$, Arto Huuskonen6), Leena Tuomisto ${ }^{6)}$

${ }^{1)}$ Kuopion yliopisto, Ympäristötieteen laitos, sjokinen@hytti.uku.fi, erkki.bjork@uku.fi

${ }^{2}$ Savonia-ammattikorkeakoulu, etunimi.sukunimi@savonia-amk.fi

${ }^{3)}$ Kuopion yliopisto, Soveltavan biotekniikan instituutti, etunimi.sukunimi@uku.fi

${ }^{4)}$ Helsingin yliopisto, Eläinlääketieteellinen tiedekunta, etunimi.sukunimi@helsinki.fi

${ }^{5)}$ Työterveyslaitos, etunimi.sukunimi@ttl.fi

${ }^{6)}$ MTT/Pohjois-Pohjanmaan tutkimusasema, etunimi.sukunimi@mtt.fi

\section{Tiivistelmä}

Pikkuvasikoiden kokonaisajankäytöstä $90 \%$ on lepoaikaa. Karjakokojen kasvaessa ja tuotantorakennusten koneellistuessa on melusta tullut huomattava fysikaalinen ympäristötekijä, joka saattaa haitata vasikoiden hyvinvointia. Melun on todettu aiheuttavan naudoilla $\mathrm{mm}$. lepoajan vähentymistä, levottomuutta ja syöntihaluttomuutta. Maa- ja metsätalousministeriön asettamien melun ohjearvojen mukaan tuotantoeläimiä ei saa jatkuvasti altistaa yli $65 \mathrm{dBA}: n$ melulle.

Tässä tutkimuksessa selvitettiin pikkuvasikoiden melualtistusta lypsykarjapihatoissa. Tutkimus toteutettiin mittaamalla melualtistusta 10 pihattonavetassa keväällä 2005. Mittaustulokset painotettiin nautojen kuuloherkkyyskäyrän mukaan $\left(\mathrm{L}_{N}\right)$ sekä vertailun vuoksi tulokset laskettiin myös ihmisen kuuloherkkyyden mukaan $\left(\mathrm{L}_{\mathrm{H}}\right)$ ja A-painotettuina $\left(\mathrm{L}_{\mathrm{A}}\right)$ sekä lineaarisena $\left(\mathrm{L}_{\text {lin }}\right)$ ilman painotusta. Ultraäänien (yli $20 \mathrm{kHz}: \mathrm{n}$ taajuisten äänien) esiintymisestä karjasuojissa on viitteittä, joten niiden esiintymistä tutkittiin. Myös N- ja Apainotusten vastaavuutta tutkittiin, koska niiden vastaavuus helpottaisi naudan melualtistuksen mittaamista.

Eri melutapahtumille saatiin hieman erilaiset tulokset A- ja N-painotettuna. A-painotus on verrannollinen ohjearvoon ja N-painotus naudan kuulemaan äänenvoimakkuuteen. Taustan melutasoksi saatiin 1 sekunnin keskiäänitasoista $62,1 \mathrm{dBA}$ ja $58,7 \mathrm{dBN}$, ilmanvaihdon $59,3 \mathrm{dBA}$ ja $56,5 \mathrm{dBN}$, ruokinnan $87,3 \mathrm{dBA}$ ja $80,8 \mathrm{dBN}$, lypsyn 61,4 dBA ja 62,4 dBN sekä lantakoneen 59,0 dBA ja 58,0 dBN. Melutapahtumien spektrit laskivat voimakkaasti korkeille taajuuksille mentäessä.

Koneellinen ruokinta on selvästi meluisampaa kuin muut tapahtumat, mutta se on hetkellinen tapahtuma pihatossa. Myös ruokintamelun hajonta oli selvästi suurin johtuen erilaisista koneista, joilla ruokinta suoritettiin. Melun ollessa painottunut korkeille $(2-10 \mathrm{kHz})$ taajuuksille A-painotus antaa N-painotusta hieman pienempiä äänitasoja. Yleensä melun ollessa painottunut alle $2 \mathrm{kHz}: n$ taajuuksille A-painotus antaa kuitenkin N-painotusta suurempia äänitasoja. Suurin osa 10 minuutin keskiäänitasoista on noin 60 - 65 dBA:n äänitasoilla.

Vasikoiden jatkuva melualtistus 1 sekunnin keskiäänitasoista laskettujen melutapahtumien mukaan jää alle 65 dBA. Kuitenkin 10 minuutin keskiäänitasoista laskettuna yli $65 \mathrm{dBA}$ äänitasoille altistutaan $30 \%$ ajasta. Karjan ruokinnan aikana melutaso oli yli $87 \mathrm{dBA}$. Huomion arvoista on, että ihmisille annetaan ohjearvoksi asuinhuoneissa 35 dBA päivällä (klo 7-22) ja yöllä 30 dBA (klo 22-7) sekä oleskelualueilla ulkona päivällä (klo 7-22) 55 dBA. Vasikoiden tarvitseman levon vuoksi meluntorjunta navetoissa, erityisesti vasikoiden karsinoissa, voisi olla suotavaa.

Pihatoissa ei todennäköisesti esiinny ultraääniä merkittävässä määrin. A-painotettu äänitaso näyttää edustavan melko hyvin naudan kuuloherkkyyden mukaista äänitasoa. Yleensä melun ollessa painottunut alle 2 kHz:n taajuuksille A-painotus antaa N-painotusta hieman suurempia äänitasoja.

Asiasanat: nautakarja, vasikat, pihatto, altistuminen: melu, äänenvoimakkuus 


\section{Johdanto}

Karjakokojen kasvaessa ja tuotantorakennusten koneellistuessa on melusta tullut huomattava ympäristötekijä karjan hyvinvoinnin kannalta. Etenkin vahvassa kasvuvaiheessa olevien vasikoiden kohdalla melu on huomattava tekijä, koska pikkuvasikoiden kokonaisajankäytöstä $90 \%$ on lepoaikaa. Maa- ja metsätalousministeriö on asettanut ohjearvoksi tuotantoeläimien hyvinvoinnille, etteivät naudat saa olla jatkuvasti melussa joka ylittää 65 dBA [1]. Tässä tutkimuksessa oli tarkoituksena tutkia vasikoiden altistumista melulle. Lisäksi tutkittiin ultraäänien (yli $20 \mathrm{kHz}: n$ taajuisten äänien) mahdollista esiintymistä pihatoissa ja tarvetta tehdä melumittauksia tämän vuoksi ultraäänialueella. Tutkimus suoritettiin osana Lypsykarjarakennusten toiminnalliset mitoitusvaihtoehdot tutkimuskokonaisuutta (MTT/Maa-ja elintarviketalouden tutkimuskeskus) ja ELKE 1 -hanketta (Eläinterveydenhuollon kehittämishanke Pohjois-Savossa).

\section{Aineisto ja menetelmät.}

Tutkimus toteutettiin tekemällä melumittauksia 10 pihattonavetassa Pohjois-Savossa. Mittaukset suoritettiin maalis-toukokuussa vuonna 2005. Pihatot, joissa mittauksia tehtiin, olivat 40 - 80 lypsylehmän tiloja ja rakenteellisesti melko samanlaisia. Koneellinen ruokinta suoritettiin eri tiloilla erilaisilla koneilla (kiskoilla tai renkailla oleva rehuvaunu, pienkuormaaja, apevaunu, mattoruokkija).

Mittaukset tehtiin Norsonic 121 -ympäristömeluanalysaattorilla mittaamalla melualtistusta yhden sekunnin, 10 sekunnin, yhden minuutin sekä 10 minuutin jaksoissa $20 \mathrm{~Hz}: n$ - $20 \mathrm{kHz}: n$ taajuuksilla terssikaistoittain. Mikrofoni asetettiin vasikoiden läheisyyteen $90 \mathrm{~cm}: n$ korkeudelle. Mikrofonissa käytettiin tuulisuojaa. Alku- ja loppukalibrointi suoritettiin Wärtsilän 5274 vakioäänilähteellä ( 94 dB, $1000 \mathrm{~Hz})$. Ympäristömeluanalysaattori oli päällä koko mittauskäynnin ajan, joka kesti aamupäivästä iltalypsyyn. Tuloksia laskettaessa mittausdatasta erotettiin melutapahtumia muistiinpanojen avulla.

Mittausdataa käsiteltiin erottamalla 1 sekunnin keskiäänitasoista melutapahtumia sekä laskemalla koko mittauskäynnin äänitasojen jakauma 10 minuutin keskiäänitasoista. Eri melutapahtumat (ruokinta, lypsy, lantakone) erotettiin muistiinpanojen perusteella vähentämällä taustamelutaso tapahtuman aikaisesta melutasosta. Taustameluun kuuluivat ilmanvaihdosta aiheutunut melu sekä eläinten aiheuttamat äänet. Ilmanvaihdon aiheuttama melutaso erotettiin taustamelusta poistamalla häiriöäänet kuten eläinten huudot ja parsien kolina.

Ruokintalaitteille laskettiin äänitasojen lisäksi äänitehotasot $\left(\mathrm{L}_{\mathrm{WA}}\right)$ kuten myös erikseen mitatuille parren lukkojen kolahduksille. Äänitehotaso on etäisyydestä riippumaton suure (lähteestä 0,282 metrin etäisyydellä oleva äänitaso), joka kuvaa lähteen melupäästöä. Koko mittauskäynnin aikaisten äänitasojen jakauma laskettiin 10 minuutin A-painotetuista keskiäänitasoista. Melutapahtumien aikaiset minimit, maksimit ja keskihajonnat laskettiin A-painotetuista 1 minuutin keskiäänitasoista.

Mittaustulokset painotettiin nautojen kuuloherkkyyskäyrän mukaan $\left(\mathrm{L}_{\mathrm{N}}\right)$ sekä vertailun vuoksi tulokset laskettiin myös ihmisen kuuloherkkyyden mukaan $\left(\mathrm{L}_{\mathrm{H}}\right)$ ja A-painotettuina $\left(\mathrm{L}_{\mathrm{A}}\right)$ sekä lineaarisena $\left(\mathrm{L}_{\text {lin }}\right)$ ilman painotusta [2]. A-painotus on mittalaitteiden käyttämä ihmisen 40-fonin samanäänekkyyskäyrän mukainen painotus ja H-painotus on ihmisen kuulokynnyksen mukainen painotus, joka vastaa $\mathrm{N}$-painotusta naudalla (kuva 1). A-painotetun äänitason ja N-painotetun äänitason vastaavuutta verrattiin, koska niiden vastaavuus helpottaisi nautojen melualtistuksen mittaamista.

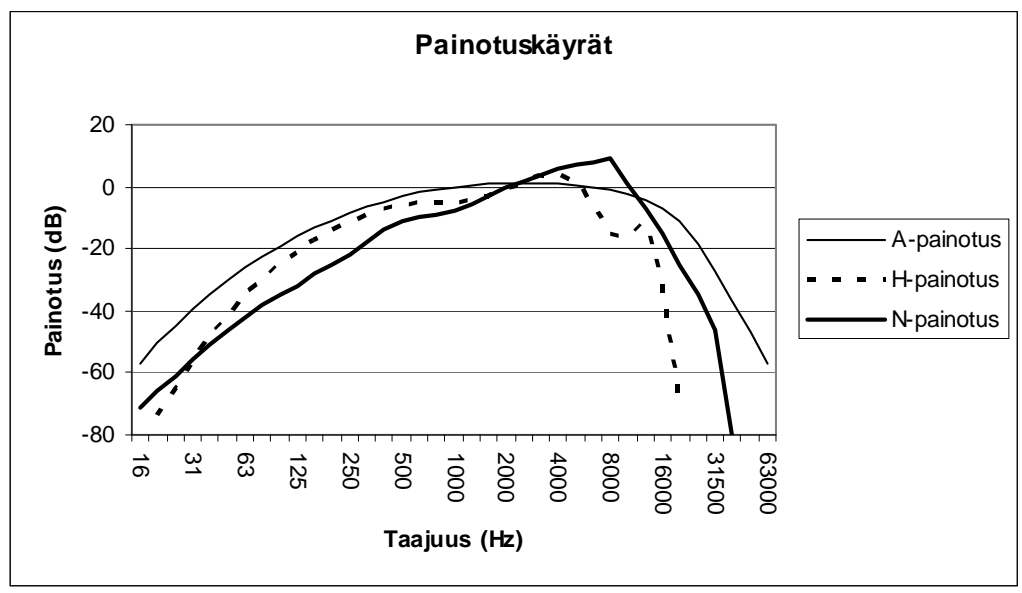

Kuva 1: Painotuskäyrät. 


\section{Tulokset ja tulosten tarkastelu}

Taulukossa 1 esitetään vasikoiden melualtistus kaikkien pihattojen eri melutapahtumien energiakeskiarvoina.

Taulukko 1: Melutapahtumien aikaiset keskiäänitasot lineaarisena sekä A-, H-, ja N-painotettuina vasikoiden läheisyydestä mitattuna.

\begin{tabular}{|l|l|l|l|l|}
\hline Tapahtuma & $\mathrm{L}_{\text {lin }}(\mathrm{dB})$ & $\mathrm{L}_{\mathrm{A}}(\mathrm{dBA})$ & $\mathrm{L}_{\mathrm{H}}(\mathrm{dBH})$ & $\mathrm{L}_{\mathrm{N}}(\mathrm{dBN})$ \\
\hline Tausta & 68,5 & 62,1 & 59,3 & 58,7 \\
\hline Ilmanvaihto & 67,4 & 59,3 & 56,9 & 56,5 \\
\hline Ruokinta & 93,3 & 87,3 & 84,0 & 80,8 \\
\hline Lypsy & 67,0 & 61,4 & 59,9 & 62,4 \\
\hline Lantakone & 63,9 & 59,0 & 57,5 & 58,0 \\
\hline
\end{tabular}

Taulukossa 2 esitetään koneellisen ruokinnan sekä parren lukkojen aiheuttamat keskimääräiset äänitehotasot.

Taulukko 2: Ruokintakoneiden ja parren lukkojen keskimääräiset äänitehotasot $\left(\mathrm{L}_{\mathrm{W}}\right)$ lineaarisena sekä A-, H-, ja Npainotettuina.

\begin{tabular}{|l|l|l|l|l|}
\hline Tapahtuma & $\mathrm{L}_{\mathrm{Wlin}}(\mathrm{dB})$ & $\mathrm{L}_{\mathrm{WA}}(\mathrm{dBA})$ & $\mathrm{L}_{\mathrm{WH}}(\mathrm{dBH})$ & $\mathrm{L}_{\mathrm{WN}}(\mathrm{dBN})$ \\
\hline Ruokintakone & 110,5 & 102,7 & 100,2 & 100,1 \\
\hline Parren lukko & 96,0 & 96,6 & 97,1 & 100,3 \\
\hline
\end{tabular}

Kuvassa 2 esitetään ilmanvaihdon, ruokinnan, lypsyn ja lantakoneen äänien spektrit 20 Hz:n - 20 kHz:n taajuuksilla vasikan kuuloherkkyydellä painotettuna.

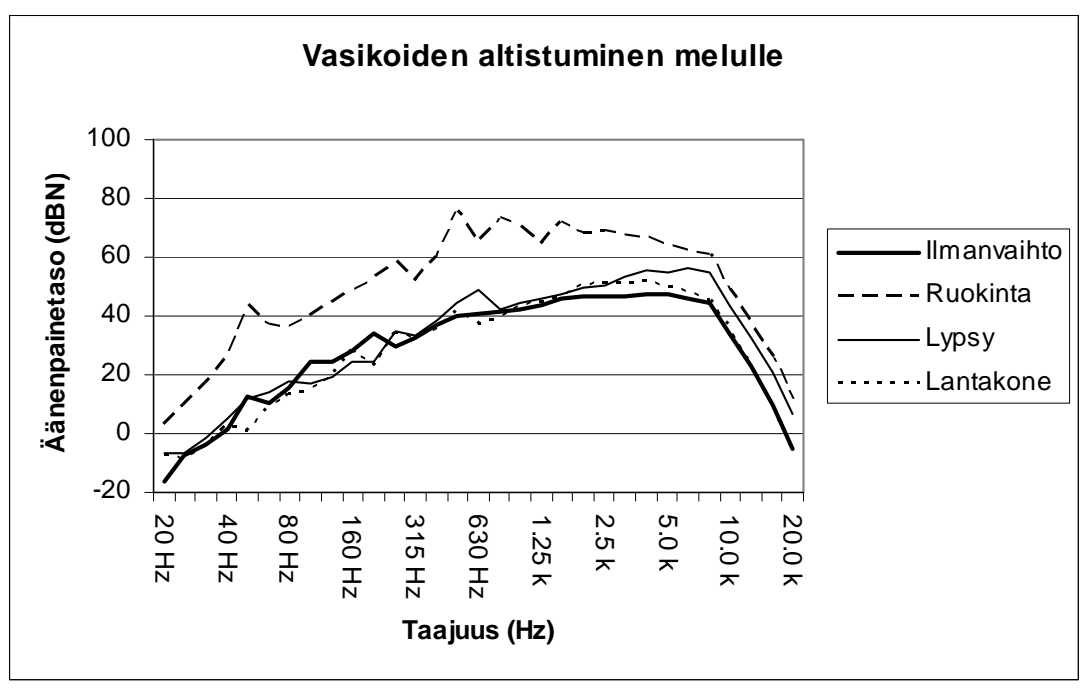

Kuva 2: Melutapahtumien spektrit $20 \mathrm{~Hz}-20 \mathrm{kHz}$ taajuuksilla N-painotettuna terssispektrinä.

Mittauskäynnin aikainen äänitasojen jakauma vasikoiden läheisyydessä mitattuna esitetään kuvassa 4 kaikkien pihattojen osalta. Minimitaso on $45 \mathrm{~dB}$ ja maksimitaso on $81 \mathrm{~dB}$. A-painotettujen keskiäänitasojen minimit ja maksimit esitetään taulukossa 3 sekä hajonnat kuvassa 5 . 


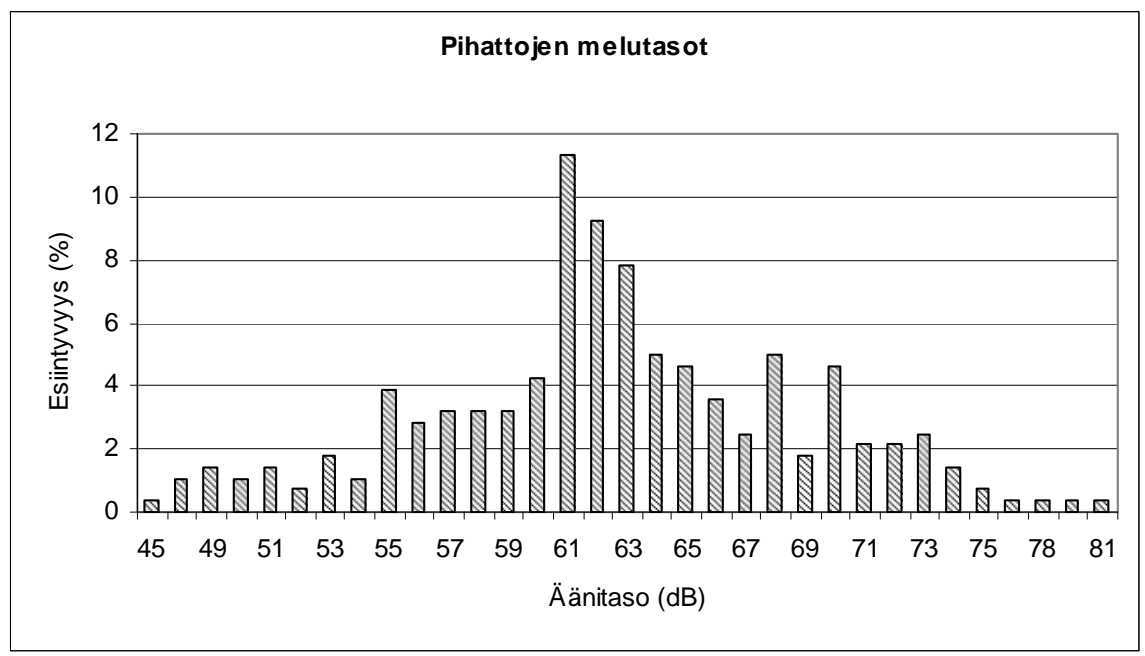

Kuva 4: Pihattojen 10 minuutin keskiäänitasojen jakauma prosentteina.

Taulukko 3: Melutapahtumien minimit, maksimit ja keskihajonnat A-painotetuista 1 minuutin keskiäänitasoista laskettuna.

\begin{tabular}{|l|l|l|l|l|}
\hline Tapahtuma & $\mathrm{L}_{\text {Aeq }}(\mathrm{dBA})$ & minimi & maksimi & hajonta \\
\hline Tausta & 62,1 & 46 & 74 & 5,0 \\
\hline Ilmanvaihto & 59,3 & 46 & 67 & 5,0 \\
\hline Ruokinta & 87,3 & 54 & 90 & 8,0 \\
\hline Lypsy & 61,4 & 56 & 72 & 3,0 \\
\hline Lantakone & 59,0 & 50 & 70 & 4,2 \\
\hline
\end{tabular}

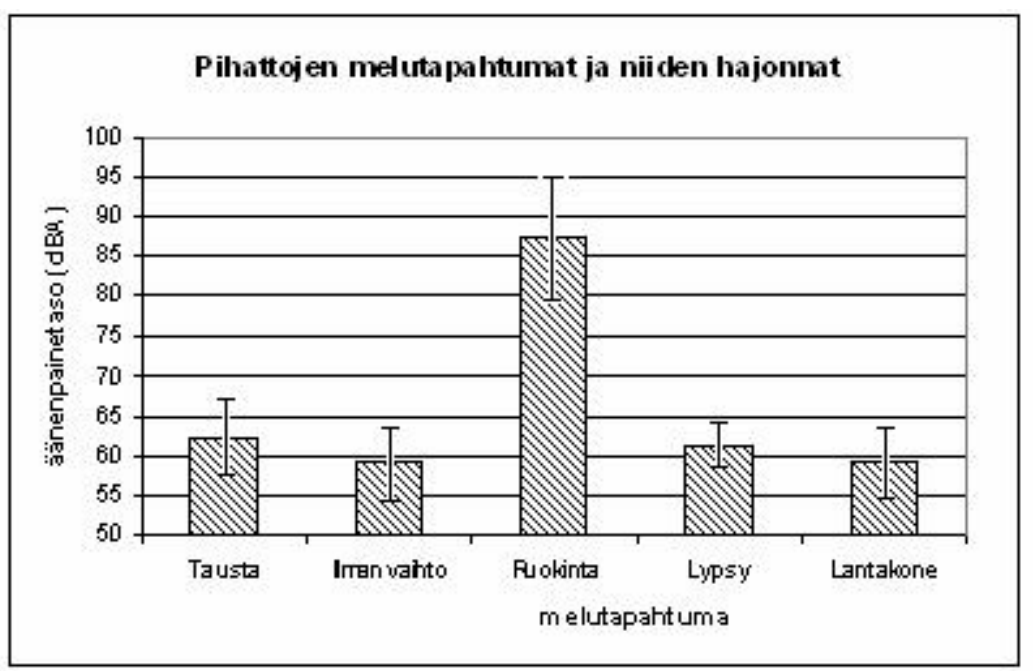

Kuva 5: Melutapahtumien keskimääräiset äänenpainetasot ja hajonnat vasikoiden läheisyydestä mitattuna.

Lähinnä A- ja N-painotetut tulokset ovat mielenkiintoisia tässä tapauksessa. A-painotettuja tuloksia verrataan ohjearvoon. Koneellinen ruokinta oli selvästi meluisampaa kuin muut tapahtumat, mutta se on vain hetkellinen tapahtuma pihatossa. Melun ollessa painottunut korkeille $(2-10 \mathrm{kHz})$ taajuuksille A-painotus antaa N-painotusta hieman pienempiä äänitasoja. Yleensä melun ollessa painottunut alle $2 \mathrm{kHz}: \mathrm{n}$ taajuuksille A-painotus antaa kuitenkin N-painotusta suurempia äänitasoja.

Naudan kuuloherkkyydellä painotettuna parren lukkojen ja ruokintalaitteiden äänitehotasot olivat samansuuruisia. Nauta kuulee parren kolahdukset 4 desibeliä voimakkaampana kuin ihminen. Ruokintalaitteet kuulostavat naudasta yli 2 desibeliä hiljaisemmilta kuin ihmisestä. 
Melutapahtumien N-painotetuista terssispektreistä näkyy äänitasojen lasku korkeilla taajuuksilla. Tästä on pääteltävissä, ettei ultraäänitaajuuksilla esiintyne merkittävässä määrin melua, koska myös naudan kuuloherkkyys laskee edelleen ultraäänitaajuuksille mentäessä.

Suurin osa 10 minuutin keskiäänitasoista oli 60 - 65 dB:n äänitasoilla. Äänitasojen hajonta oli suurinta ruokinnassa, koska ruokinta suoritettiin hyvin erilaisilla koneilla. Muiden melutapahtumien yhteydessä hajonnatkaan eivät ylittäneet $65 \mathrm{~dB}: a ̈$.

\section{Johtopäätökset}

Vasikat eivät altistu jatkuvasti yli $65 \mathrm{dBA}: n$ tasoille melutapahtumien A-painotettujen energiakeskiarvojen perusteella. Kuitenkin 10 minuutin keskiäänitasoista laskettuna yli 65 dBA:n äänitasoille altistutaan $30 \%$ ajasta. 10 minuutin keskiäänitasoissa on mukana kaikki mittausaikana esiintyneet äänet kuten myös mittaajista ja muista pihatoissa käyneistä ihmisistä aiheutuneet äänet. Eri pihatoissa melutasot erosivat riippuen lähinnä eläinten käyttäytymisestä, mutta myös ilmastoinnin aiheuttamasta melusta.

Lypsyn aikaisen äänitason hajonta on pieni. Lypsyn aiheuttamat melutasot eivät siis juuri poikkea toisistaan eri pihatoissa. Ruokinnan aikainen äänitason hajonta on suuri, koska ruokinta suoritettiin hyvin erilaisilla koneilla.

Huomion arvoista on, että ihmisille annetaan ohjearvoksi asuinhuoneissa 35 dBA päivällä (klo 7-22) ja yöllä ohjearvo on $30 \mathrm{dBA}$ (klo 22-7) sekä oleskelualueilla ulkona päivällä (klo 7-22) $55 \mathrm{dBA}$. Vasikoiden tarvitseman levon vuoksi melun torjunta navetoissa, erityisesti vasikoiden karsinoissa, voisi olla suotavaa.

Pihatoissa ei esiinny todennäköisesti ultraääniä merkittävässä määrin. A-painotettu äänitaso näyttää edustavan melko hyvin naudan kuuloherkkyyden mukaista äänitasoa.

\section{Kirjallisuus}

[1] MMMA 3.6.2002/6/EEO/2002

[2] Heffner, R.S. \& Heffner, E.H. 1983. Hearing in Large Mammals Horse (Equus caballus) and Cattle (Bos taurus). Behavioral Neuroscience 97: 299-309. 